\title{
Does Welfare Affect Family Processes and Adolescent Adjustment?
}

\author{
Ariel Kalil and Jacquelynne S. Eccles
}

\begin{abstract}
Recent welfare reform legislation requires increased parental work effort and imposes time limits on the receipt of federal assistance. These changes were based in part on assumptions that parental welfare receipt may be negatively related to family processes and children's attitudes and behaviors. Currently, researchers know little about the effects of welfare by itself relative to the effects of related variables such as family demographic characteristics, economic strain, and neighborhood factors on processes among families with adolescent children. This study investigates parenting behaviors, parent-adolescent relationships, and adolescent attitudes and behaviors in three family types. Families of adolescents ages 11-15 who received income from Aid to Families with Dependent Children (AFDC) in the previous 12 months are compared with poor families who have not received AFDC in the last year and with families who are neither poor nor welfare dependent. We found minimal support for the hypothesis that welfare is negatively related to family processes and adolescent attitudes and behaviors, although mothers receiving welfare report fewer effective parent management practices than their poor non-welfare counterparts. Implications of the findings for current social policy debates are discussed.
\end{abstract}

\section{INTRODUCTION}

The Personal Responsibility and Work Opportunity Reconciliation Act of 1996 (P.L. 104-193) ended the federal guarantee of cash assistance and replaced an entitlement program, Aid to Families with Dependent Children (AFDC), with a capped block grant, Temporary Assistance for Needy Families (TANF). This act places a 5 year lifetime limit on the receipt of federally funded welfare benefits and requires most welfare mothers to work within 2 years of entrance into the program. These changes reflect, in part, commonly held beliefs about the effects of welfare on families and children. Proponents of the new laws assert that welfare receipt undermines families by discouraging work, compromising family stability, and encouraging negative behaviors among children. Such views often derive from negative stereotypes of welfare-reliant families that portray mothers as irresponsible parents who are raising their children outside the mainstream of American family values (Salomon, 1996; Sidel, 1996). According to these views, dismantling the entitlement to welfare will provide children with constructive role models and will change the belief systems and behaviors of families, thereby enhancing poor children's development and socioeconomic prospects (Kaus, 1992; Mead, 1992; Murray, 1984).

In contrast, opponents of the recent welfare policy changes argue that it is not welfare receipt per se, but related characteristics such as unemployment, economic stress, and poor neighborhoods, that may be negatively related to outcomes for parents and children and thus may account for differences observed between welfare families and their non-welfare counterparts. In this view, misguided policy changes that aim to eliminate welfare as a source of income and consequently deepen poverty and economic suffering among low-income families may have adverse effects on families' home environments, mothers' parenting practices, and children's development (Bane, 1997; Collins \& Aber, 1997; Edelman, 1997).

The purpose of the present article is to determine whether welfare receipt by itself is related to family processes and adolescent attitudes and behaviors net of related family demographic, economic, and neighborhood characteristics. In this way, we test the presumption that welfare-reliant mothers are less good at parenting and that their children display attitudes and behaviors that could compromise future socioeconomic prospects. Current empirical evidence is limited in its support of either side of the ongoing public policy debate. Researchers know little about whether and how welfare is related to family processes and child development; the existing literature is particularly sparse regarding such processes in families with adolescent children. Identifying potential differences in family functioning is an important task regardless of whether they are related to welfare, as suggested by some scholars (Mead, 1992; Murray, 1984), or whether differences are a function of welfare correlates such as economic strain or neighborhood characteristics. Such results can provide direction for policies aimed at improving family well-being.

(c) 1998 by the Society for Research in Child Development, Inc. All rights reserved. 0009-3920/98/6906-0005\$01.00 
As suggested above, one key issue in this debate is whether welfare is related to family processes independent of other economic and sociodemographic factors that co-occur with welfare receipt. This issue involves selection effects-unmeasured differences between families who receive welfare and those who do not-that make it difficult to determine whether welfare by itself affects families, or whether observed differences are actually due to family differences in employment, economic circumstances, or poor neighborhood contexts (Phillips \& Bridgman, 1997). Existing data to answer this question are limited in their ranges of potential selection effects, indicators of family processes and child development, and age ranges of children.

This study aims to address this gap by using data from a sample of urban, low-income families with adolescent children to examine differences in family processes and child development in poor welfare, poor non-welfare, and non-poor families. These data include measures of welfare, economic circumstances, neighborhood context, family processes, adolescent attitudes and behaviors, and a range of family background factors known to co-occur with welfare receipt. Our major interest is in determining whether welfare receipt by itself is related to family processes and adolescent development net of a range of theoretically relevant selection effects, thereby helping to inform the current debate over the effects of welfare on families.

\section{Background}

A small and equivocal body of research suggests that welfare receipt by itself may be negatively related to family processes and children's development. Two studies observed that parents in welfare families provided their preschool children with less intellectual stimulation and emotional support than did parents in families that were poor but not welfare dependent as well as parents in families that were neither poor nor welfare dependent (Moore, Zaslow, Coiro, Miller, \& Magenheim, 1995; Zill, Moore, Smith, Stief, \& Coiro, 1991). These studies used data on preschoolers from an experimental evaluation of 790 participants in the federal Job Opportunities and Basic Skills (JOBS) program and from preschoolers in a national data set, the National Longitudinal Survey of Youth-Child Supplement (NLSY-CS). However, Klebanov, Brooks-Gunn, and Duncan (1994), using data from an eight site study of 3-year-olds $(n=895)$, did not find any significant effects of welfare on similar measures of the home environment in analyses that controlled for family income and neighborhood poverty. Moore et al. (1995) also reported that the welfare-dependent children in the JOBS evaluation had lower scores on a measure of cognitive development compared to non-poor preschoolers in a national data set. Moore and Driscoll (1996), using national data on children ages 9 to 14 , found welfare receipt to be associated with worse reading, math, and behavior scores for White children and with worse reading scores for Black children, although these differences diminished once selection effects (including depth and duration of family poverty) were taken into account. In the Baltimore Study of Teen Motherhood, mothers' welfare receipt was associated with their teenage children's tendency to drop out of high school and display behavior problems (Furstenberg, Brooks-Gunn, \& Morgan, 1987).

Studies that have documented the association of welfare with children's development also suggest that the timing of welfare receipt in a child's life may be an important factor. Zill et al. (1991) provided some evidence that developmental problems among children in AFDC families appear to worsen with age. For example, among welfare-reliant families in the NLSY-CS, older children had more school behavior problems than did their younger counterparts. Similarly, Yeung, Brooks-Gunn, Duncan, and Smith (1996), using data from the Panel Study of Income Dynamics (PSID), found that welfare receipt during middle childhood (ages 6 to 10) was associated with fewer years of completed schooling and increased risk of teenage childbearing, controlling for a range of background factors including family income. In contrast, welfare receipt during early childhood had no effects on these outcomes.

Although these studies provide some information about the possible effects of welfare on children's behavior and adjustment, the lack of consistent evidence and the variability in selection factors controlled for across these studies leave the issue of welfare effects per se unresolved. Furthermore, these studies primarily examined how young children are parented and how preschoolers develop. As such, none provides evidence for or against the hypothesis that welfare is related to the quality of parent-child relationships or how older children are parented. Importantly, none provides any evidence about whether adolescents in welfare-reliant families demonstrate attitudes and behaviors that could jeopardize their future prospects. In part, this is a function of the available data; the NLSY-CS and the PSID lack measures of adolescent attitudes, parent-adolescent relationships, and specific parenting practices, such as supervision and monitoring, that are relevant to adolescent development.

Importantly, as stated previously, the interpretation of evidence suggesting a relation between wel- 
fare receipt and family processes is complicated by the issue of selection effects. Considerable research in sociology and developmental psychology has documented the potentially negative effects of welfare correlates such as poverty, economic strain, impoverished neighborhood contexts, and other related background variables on family processes and children's development (Brooks-Gunn, Duncan, Klebanov, \& Sealand, 1993; Conger \& Elder, 1994; Conger, Ge, Elder, Lorenz, \& Simons, 1994; Duncan \& BrooksGunn, 1997; Klebanov et al., 1994; McLanahan \& Sandefur, 1994). Poverty and economic strain are expected to negatively affect parents' discipline and monitoring behaviors, parental involvement in children's lives, and parent-child relationships (Connell, Spencer, \& Aber, 1994; Eccles, Furstenberg, McCarthy, \& Lord, 1992; Elder, Eccles, Ardelt, \& Lord, 1995; Jessor, 1993; McLoyd, 1990; Sampson \& Laub, 1994). These parenting behaviors have important implications for children's academic achievement and aspirations, conduct problems and delinquency, and behavioral and psychological well-being (Comer \& Haynes, 1991; Elliott, Huizinga, \& Ageton, 1985; Loeber \& Stouthamer-Loeber, 1986; Patterson, DeBaryshe, \& Ramsey, 1989; Patterson \& StouthamerLoeber, 1984). Neighborhoods are hypothesized to affect family processes via the collective behavior and values of neighborhood residents as well as the availability of positive role models and institutional resources in the community (Brooks-Gunn et al., 1993; Furstenberg, 1994; Klebanov et al., 1994; Wilson, 1987). Specifically, the presence of fewer adult role models and institutional resources in the community is expected to diminish family well-being.

Lastly, substantial evidence from various literatures posits that welfare correlates at the family socioeconomic and demographic level (e.g., single-parent status, parental employment and education, race or ethnicity, household crowding, the ages of parent and child) may also affect family processes and adolescent development. For example, McLanahan and Sandefur (1994) linked single parenthood to less parental monitoring of and investment in children, leading to an increase in the chances that adolescents will become involved in delinquent or nonproductive activities. Parental employment is generally associated with positive outcomes, such as family cohesion and youth self-esteem (Alessandri, 1992; Hoffman, 1989; Repetti, Matthews, \& Waldron, 1989), and parental education level has been widely linked to children's academic success (Weston, 1989). Some research has documented racial differences in family processes as well as adolescent academic success and involvement in problem behavior (Condran \& Furstenberg, 1994; Schneider \& Coleman, 1993), although there is little consensus on why these differences occur. Elder et al. (1995) attributed observed differences in parent management practices to differences in neighborhood safety among Black and White families.

In sum, substantial empirical evidence converges on the potentially negative effects of welfare correlates such as poverty and economic strain on family processes and child development. Additional studies hypothesize that related neighborhood and family socioeconomic and demographic characteristics affect these outcomes. However, the lack of consistency in controlling for these selection effects has clouded efforts to determine whether welfare receipt by itself is related to family processes. As such, negative stereotypes about welfare-reliant families continue to infuse policy debates (Salomon, 1996; Sidel, 1996). Importantly, few studies have investigated the potential effects of welfare on adolescent children and their parents, and no study of welfare families has examined parent-adolescent relationships and parenting behaviors relevant to successful adolescent development. Yeung et al. (1996) hypothesized that adolescents in welfare-reliant families could begin to perceive of welfare receipt as a viable life course and might adopt attitudes or engage in behaviors that foreclose future options. We currently know little about whether and how preteen and early adolescents are affected by welfare as they begin to make decisions about and prepare for adult roles.

We build upon and extend earlier research in several ways. First, we examine the effects of welfare receipt during adolescence. Second, we investigate the relation of welfare to a wide set of family processes, including multiple measures of the parent-adolescent relationship; multiple, theoretically relevant parenting behaviors; and key indicators of adolescents' values, attitudes, and behaviors. These processes are germane to family well-being and successful adolescent development. Finally, we address the issue of selection effects by controlling for a wide range of economic and noneconomic factors correlated with welfare (including economic strain, neighborhood context, parent and child socioeconomic and demographic characteristics) in our multivariate analyses to better understand the unique associations of welfare receipt with family processes and adolescent attitudes and behaviors.

\section{METHOD}

Participants

The subsample for this study was derived from a larger sample of 489 families with a child $11-15$ years 
of age who agreed to participate in the Philadelphia Family Management Study, a cross-sectional study conducted in 1990 and designed to examine the impact of various parent management strategies on adolescent development in high-risk environments. The subsample used for the present study consists of 320 African American and non-Hispanic White families in which the "primary caregiver" (e.g., the person in the household who knew the most about the adolescent) was the target child's mother (as opposed to the target child's grandparent, foster parent, father, or other relative). In terms of household socioeconomic status, this subsample was representative of the larger sample from which it was drawn.

\section{Sampling and Procedures}

As a way of minimizing the costs of sampling households with young adolescents within designated census tracts, the Family Management Study was nested into an existing study that was designed to evaluate the impact of family planning services on teens' sexual practices in several inner-city neighborhoods of Philadelphia. A sample of 65 census tracts (out of 365 total) was drawn from four areas of Philadelphia. These sections of the city were selected because they surrounded the family planning clinics that were part of the evaluation, although they were sufficiently broad to include a large part of the less affluent part of the city. Each of the four areas is different from the others and contains a varied set of small neighborhoods. However, these areas are not entirely representative of the city as the sampling frame does not include the high-income White areas of the city or the most distressed, highly concentrated poverty areas of North Philadelphia. Nonetheless, the sample does encompass some of the poorest White sections in Philadelphia and a large range of Black neighborhoods. Because of this sampling method, the census tracts in the four areas from which the sample was drawn have a higher proportion of Black families, contain a larger proportion of poor families, and have fewer highly educated adults than the city of Philadelphia as a whole.

Within each of the 65 census tracts, one to three block groups were randomly selected. These block groups provided the final sample that was used to screen for eligible families. A street address listing was compiled using census maps of the selected block groups. From a reverse telephone directory, an enumeration was made by phone of all households with listed phone numbers. These households were then called to identify those with a youth in the target age range. This procedure yielded 805 potentially eli- gible families. A $10 \%$ sample of the families with no phones or unlisted numbers was randomly drawn and screened in person by interviewers for eligibility. Among the houses with unlisted or no phones, 61 eligible households were identified and 47 were successfully interviewed. These families were less well educated and poorer on average than the rest of the sample.

All families received a letter describing the objectives of the research, encouraging participation, and offering an incentive for taking part in the study. Completed interviews were obtained from $78 \%$ of either an eligible teen or a parent, although it was not always possible to interview both. In all, 489 parent and teen pairs completed interviews.

In each household, the mother and a target adolescent were interviewed by a trained interviewer. Both of these participants also completed a self-administered questionnaire while the interviewer was at the house. The interview and the self-administered questionnaire consisted of items assessing parent and child perceptions of the neighborhood, parent management strategies, family environment and relationships, and parent and child adjustment. Each mother received $\$ 40$ for her participation in the study; each adolescent was paid $\$ 20$.

\section{Measures}

\section{Scale Construction and Data Reduction}

Scale construction for the parent and adolescent measures occurred via a multistep process involving first- and second-order data reduction. First-order data reduction involved the creation of conceptually based scales via exploratory factor analyses. Final scales at the first step were determined based on satisfactory factor loadings (greater than .6) of variables on constructs and sufficiently high internal reliabilities of constructs. To obtain higher-order operational constructs for the parent and adolescent measures, second-order scale creation was performed. The set of composite scales was submitted to factor analysis, and second-order composite scales were computed as an average of the standardized subscales. The higher-order factor structures were examined for patterns of convergent and divergent validity of the measures and provided the basis for the creation of the composite constructs. Adequate psychometric properties for each of the first- and second-order scale composites were obtained (see Lord [1994] for a complete description of data reduction and factor loadings for first- and second-order factor analyses). The composite measures in this investigation are described below. 


\section{Dependent Variables}

Measures of parenting. According to developmental psychologists, the triumvirate of "good" parenting behaviors for adolescents consists of parental nurturance, consistent discipline, and appropriate provision of autonomy (Baumrind, 1989, 1991; Lempers, ClarkLempers, \& Simons, 1989; Maccoby \& Martin, 1983). Each of these aspects of parenting has been linked to a variety of developmental outcomes for children. This investigation made use of complementary behaviors comprising two of these basic dimensions of parenting-management effectiveness and parent nurturance. These measures were designed for the Family Management Study by the investigators (Eccles et al., 1992; Furstenberg, 1990). All measures were comprised of questions with Likert-type response scales.

Management effectiveness refers to parental monitoring and discipline of adolescents. A wide body of literature has cited these parenting practices as important predictors of successful adolescent development, particularly in high-risk settings (Eccles et al., 1992; Furstenberg, 1990; Jessor, 1993; McLanahan \& Sandefur, 1994; McLoyd, 1990). We used a composite scale reflecting multiple aspects of management effectiveness, including consistency in discipline behaviors, parental monitoring of the adolescent's activities in and outside the home, and mothers' perceptions of characteristics of the adolescent that impede effective management. This 16 item parentreport composite scale had an internal reliability (measured by Cronbach alpha) of .64, indicating moderate reliability. Higher scores on this scale reflect greater management effectiveness.

Parent nurturance comprises home-based parenting activities, such as the encouragement of competence and working with the adolescents on activities, as well as out-of-home parenting activities, including the involvement of children in outside programs and parent verbal and nonverbal actions that warn the child about dangers and risks (Elder et al., 1995). These positive behaviors have been linked to successful adolescent development, particularly in the areas of adolescent self-esteem and academic achievement (Comer \& Haynes, 1991; Dornbusch, Ritter, Leiderman, Roberts, \& Fraleigh, 1987; Eccles et al., 1992; Steinberg, Lamborn, Dornbusch, \& Darling, 1992). We measured parent nurturance with a 24 item parent-report composite scale reflecting home-based activities (mothers' encouragement of their adolescents' special talents, and the extent to which mothers spent time with their child working on this activity, provided opportunities for their child to get involved in programs that would foster these talents, and praised and encouraged their child's pursuit of these talents), out-of-home parenting activities (the extent to which the mother used prevention strategies for keeping her child from getting involved in worrisome activities), and, finally, the amount of time mothers and adolescents spent doing enjoyable things together in and outside the home. Cronbach alpha for the 24 item standardized composite measure was .82 . Higher scores on this measure indicate more parental nurturance.

Measures of the parent-adolescent relationship. We examined two indicators of the parent-adolescent relationship. The first, a parent report, assessed an affective component of the parent-adolescent relationship with a four item scale assessing the amount of parent-child conflict occurring over such things as spending money or report card results. On this Likert scale, 1 = "almost never" and 5 = "almost always." We also examined the frequency of parent-adolescent communication, using a five item adolescent-report scale. This measure asked about the extent of communication about the adolescent's feelings, plans for the future, and problems at school, for example. On this Likert scale, $1=$ "almost never" and $6=$ "almost every day." The internal consistency of these two scales was .75 and .68 , respectively. Together, these two scales reflect aspects of parent-adolescent relationships that are a part of the normative adolescent experience and that have been linked to authoritative parenting and healthy adolescent development (Montemayor, 1983). For example, teens who report feeling relatively more close with their parents have better psychosocial development, including psychological adjustment and greater behavioral competencies such as school performance. Conversely, they have lower reports of psychological and social problems, including depression and deviant behavior (Baumrind, 1991; Steinberg, 1990).

Measures of adolescent attitudes and behavior. We investigate two adolescent attitudes that represent adherence to mainstream values toward social behavior and future success. The first is a 20 item scale (alpha $=.84$ ) assessing the extent of adolescents' moral disengagement. Representative items include "It's okay to lie if it will keep your friends out of trouble with teachers, parents, or the police," and "No one loses anything when stereo equipment is stolen from the store." This 5 point Likert scale is coded such that higher scores indicate greater moral disengagement. The second is a four item scale (alpha $=.62$ ) that measures the adolescent's perception that activities such as getting good grades and furthering one's education would help him or her get ahead in life. This 4 
point Likert scale was coded such that higher scores indicate a stronger belief in the importance of education. Wilson (1987) argued that adolescents living in social environments in which few adult role models hold steady jobs and where participation in illegal activities is common may be more likely to develop non-mainstream attitudes or alternative survival strategies.

The two adolescent behaviors we investigate are adolescents' academic performance and participation in problem behavior. Adolescent academic performance was created as a composite of mothers' and adolescents' reports of academic grades, retentions, and promotions, and the interviewers' perceptions of the adolescents' cognitive skills. A composite academic measure was created by averaging the standardized parent, adolescent, and interviewer reports. Higher scores indicate better academic performance. Cronbach alpha for this composite measure was .73.

An indicator of adolescent problem behavior was derived from the adolescents' report of the extent of their participation in delinquent behaviors, risky behaviors, and substance use. These items were derived and adapted from the National Youth Survey (Elliott et al., 1985). Based on a conceptual scheme outlined by Elliott and his colleagues (Elliott et al., 1985), items were conceptually organized into three subscales: delinquent behaviors (e.g., theft, prostitution, drug dealing, vandalism), risky behaviors (e.g., going to court, running away, engaging in sex), and substance abuse (e.g., alcohol use, marijuana use). These subscales were confirmed by exploratory factor analysis. The composite problem behavior measure was created by averaging these three subscales. Higher scores indicate more problem behavior. Internal consistency for this composite measure was .71. Adolescents' self-report of involvement in problem behaviors was used exclusively, because self-report indicators have been shown to have adequate reliability and validity when compared with other social science measures (Elliott, Huizinga, \& Menard, 1989). Indeed, given that parents may be mostly unaware of their child's involvement in problem behaviors, the children themselves may be the most reliable reporters. Although the potential for underreporting of involvement in such activities exists, Elliott and his colleagues noted that deliberate falsification is relatively rare.

\section{Independent Measures}

Family type. We are primarily interested in determining whether family processes and adolescent adjustment differ among welfare families, poor non- welfare families, and non-poor families. We therefore assigned families to one of these three groups. Because the public debate over welfare reform has focused almost exclusively on AFDC cash assistance, and because the major provision of the new welfare law eliminates AFDC and creates a block grant for states to provide time-limited cash assistance, we use families' receipt of AFDC, and not other types of means-tested assistance such as Food Stamps, Medicaid, and Supplemental Security Income, to determine welfare status (U.S. House of Representatives, 1996).

Mothers' welfare status was determined by their report of whether they had received income from AFDC in the previous 12 months $(N=52)$. Poor nonwelfare families are those whose total family income leaves them below the poverty threshold, but who did not receive any AFDC income in the previous 12 months $(N=38)$. Information on total family income was coded in a categorical fashion in the survey; families were therefore assigned the value of the midpoint in each of their respective categories. ${ }^{1}$ Federal guidelines for constructing poverty thresholds per family size were obtained from the U.S. Bureau of the Census (1993). The third family type is non-poor families $(N=230)$. We construct dummy variables for multiple regression analyses (described below); in these analyses, welfare families are the reference group.

Neighborhood characteristics. We control for a number of neighborhood characteristics that have been hypothesized to affect family processes and that are likely to co-occur with poverty and welfare receipt (Furstenberg, 1990; Wilson, 1987). These measures include census-tract demographic variables as well as subjective indicators of neighborhood quality obtained directly from respondents. ${ }^{2}$ The two census tract-level demographic indicators included in the analyses are the percentages of poor families and vacant houses in the respondent's census tract. Together, these measures represent characteristics of individuals as well as structures in the neighborhood.

1. The original variable had the following seven categories: $1=$ less than $\$ 5,000 ; 2=\$ 5,000-\$ 9,999 ; 3=\$ 10,000-\$ 19,999$; $4=\$ 20,000-\$ 29,999 ; 5=\$ 30,000-\$ 39,999 ; 6=\$ 40,000-\$ 49,999$; $7=\$ 50,000$ or more. The midpoint for category 1 was set at $\$ 2,500$.

2. No general consensus exists on how to define neighborhoods (Brewster, 1994). Although the use of census tracts to define neighborhoods has been criticized on the grounds that they do not accurately capture the patterns of residents' interaction and behaviors, they are similar to neighborhoods in that they are contiguous, geographically compact, and relatively homogeneous. The data are also free of substantial measurement error (Brewster, 1994). We follow Furstenberg's (1990) suggestion to use both individual and aggregate definitions of neighborhoods. 
The respondent-report neighborhood measures included in the analyses were indicators of neighborhood problems and social control. Neighborhood problems is a 23 item scale measuring the extent of, for example, vandalism, drug dealing, and high unemployment in the neighborhood. This measure was coded as the average score on a 3 point Likert scale such that 1 = "a big problem" and 3 = "not a problem." Cronbach alpha for this measure was .93. Social control is a five item indicator assessing the likelihood that respondents' neighbors would do something if, for example, the respondent's child was getting into trouble. This measure was coded as the average on a 4 point Likert scale such that $1=$ "very unlikely" and $4=$ "very likely." Cronbach alpha for this measure was .83 .

Economic characteristics. We include two indicators of family economic circumstances. The first, welfare history, is a continuous variable representing the total number of years the family has received AFDC since the adolescent's birth, due to evidence that duration of welfare receipt can affect family functioning and youth behavior (Ensminger, 1995; Furstenberg et al., 1987; Zill et al., 1991). Economic strain was measured as the average of three items on a 4 point Likert scale (Cronbach alpha $=.72$ ). These items assessed the degree of difficulty respondents had paying bills in the last month, the amount of money generally left at the end of the month, and respondents' worries about paying for things. Higher scores indicate less economic strain. Together, these variables represent a good indication of families' long-term economic circumstances and their subjective interpretation of these circumstances. A number of researchers (e.g., Conger et al., 1994; Elder et al., 1995; McLoyd \& Wilson, 1991) have argued that these subjective assessments may be more powerful predictors of family functioning than static measures of family income. ${ }^{3}$

Family demographic characteristics. Our analyses also control for a number of family and individual demographic characteristics that may co-occur with current welfare use and that are also known to be related to the dependent measures in the present study (Duncan \& Brooks-Gunn, 1997). As with neighborhood context and family economic characteristics,

\footnotetext{
3. Note that we do not include family income as a predictor because it was used to construct the "family type" dummy variables (poor welfare, poor non-welfare, non-poor). However, analyses (not reported here) indicate that non-poor families have significantly higher incomes on average (mean $=\$ 30,740$ / year) than both poor non-welfare families (mean $=\$ 9,210 /$ year) and poor welfare families (mean $=\$ 6,010 /$ year). Welfare and poor non-welfare families do not have significantly different average family incomes.
}

these demographic characteristics are important to control for in a multivariate analysis to the extent that they account for differences between welfare and non-welfare families. At the family level, we include two variables. First, we include a dummy variable for single-parent status, coded as married or living with a partner (" 0 ") versus single (" 1 "). McLanahan and Sandefur (1994) provided an extensive summary of the literature suggesting that children in singleparent families fare worse than children in families with both original parents present. Second, we measure crowding, an important indicator of resourcesharing in the household (Corcoran \& Bogess, 1994). This variable is indexed by the number of people in the household divided by the number of bedrooms.

At the individual level, we include four maternal and two adolescent characteristics. Mothers' characteristics include her race (coded " 0 " if non-Hispanic White and " 1 " if African American), education (possession of high school degree or a GED) $(0=$ no; $1=$ yes $)$, current employment status $(0=$ not employed; 1 = employed), and age, a continuous variable. Adolescents' gender (boys coded " 0 ") and age were also controlled for in the analysis.

\section{RESULTS}

The analysis is divided into two sections. First, we compare the independent and dependent variables across the three family types. This is followed by a multivariate analysis to examine the independent contribution of each of the four sets of explanatory variables-(1) individual and family demographic characteristics, (2) family economic characteristics, (3) neighborhood variables, and (4) family welfare status - to the family processes and adolescent outcomes.

\section{Comparison of Independent and Dependent Variables across Family Types}

Table 1 presents means and standard deviations for the predictor and outcome variables. Omnibus tests of group differences were conducted using oneway analysis of variance procedures. For all analyses in which the overall $F$ test was significant, we present the pairs of means that are significantly different at the .05 level based on the Bonferroni multiple comparison procedure. These differences are indicated in the far right column. Although there are theoretically expected differences in the family demographic characteristics, the most prominent result is the similarity of family and individual functioning across the three family types. However, the sensitivity to sample size 
Table 1 Comparison of Family Types on Outcomes and Explanatory Variables: Unadjusted Means

\begin{tabular}{|c|c|c|c|c|c|c|c|}
\hline \multirow[b]{2}{*}{ Variable } & \multicolumn{2}{|c|}{ Welfare } & \multicolumn{2}{|c|}{$\begin{array}{c}\text { Poor } \\
\text { Non-Welfare }\end{array}$} & \multicolumn{2}{|c|}{ Non-Poor } & \multirow{2}{*}{$\begin{array}{l}\text { Significant } \\
\text { Differences }\end{array}$} \\
\hline & $M$ & $S D$ & $M$ & $S D$ & $M$ & $S D$ & \\
\hline \multicolumn{8}{|l|}{ Outcomes: } \\
\hline Nurturance & -.01 & .70 & -.17 & .81 & .07 & .67 & n.s. \\
\hline Management & -.15 & .55 & .15 & .62 & -.03 & .64 & n.s. \\
\hline Conflict & 2.82 & .82 & 2.57 & .81 & 2.48 & .71 & $\mathrm{~b}$ \\
\hline Communication & 3.48 & 1.06 & 3.25 & 1.13 & 3.38 & 1.05 & n.s. \\
\hline Moral disengagement & 2.49 & .56 & 2.37 & .44 & 2.38 & .51 & $n . s$. \\
\hline Importance of school & 3.64 & .38 & 3.41 & .61 & 3.56 & .49 & $n . s$. \\
\hline Academic achievement & -.21 & .71 & -.17 & .74 & .14 & .79 & $\mathrm{~b}$ \\
\hline Problem behavior & -.01 & .53 & .10 & .86 & -.03 & .66 & n.s. \\
\hline \multicolumn{8}{|l|}{ Neighborhood variables: } \\
\hline Poor families (\%) & 24.78 & 11.09 & 25.11 & 12.22 & 18.60 & 9.60 & $b, c$ \\
\hline Vacant houses (\%) & 13.23 & 4.74 & 13.98 & 4.86 & 12.01 & 3.32 & $\mathrm{c}$ \\
\hline Neighborhood problems & 2.02 & .43 & 1.95 & .43 & 2.09 & .41 & n.s. \\
\hline Social control & 3.12 & .61 & 2.96 & .72 & 3.27 & .61 & c \\
\hline \multicolumn{8}{|l|}{ Economic characteristics: } \\
\hline Economic strain & 2.15 & .75 & 2.23 & .77 & 2.71 & .84 & $b, c$ \\
\hline Welfare history (years) & 3.98 & 1.46 & 1.68 & 1.71 & .67 & 1.31 & $a, b, c$ \\
\hline \multicolumn{8}{|l|}{ Family variables: } \\
\hline Two-parent structure (\%) & .08 & .27 & .32 & .47 & .51 & .50 & $b, c$ \\
\hline Crowding & 1.79 & .64 & 1.79 & .77 & 1.45 & .60 & $b, c$ \\
\hline \multicolumn{8}{|l|}{ Mother variables: } \\
\hline Race (\% Black) & .88 & .33 & .76 & .44 & .54 & .50 & b, c \\
\hline H.S. degree (\%) & .76 & .43 & .74 & .45 & .91 & .29 & $\mathrm{~b}, \mathrm{c}$ \\
\hline Age & 33.58 & 5.74 & 36.24 & 7.04 & 36.53 & 5.34 & b \\
\hline Employed (\%) & .17 & .38 & .66 & .48 & .78 & .42 & $a, b$ \\
\hline \multicolumn{8}{|l|}{ Adolescent variables: } \\
\hline Gender ( $\%$ female) & .54 & .50 & .41 & .50 & .54 & .50 & n.s. \\
\hline Age & 13.42 & 1.27 & 13.71 & 1.09 & 13.46 & 1.15 & n.s. \\
\hline
\end{tabular}

Note: $n . s .=$ not significant. The Bonferroni adjustment for multiple comparisons was used with an alpha level of .05. The letter " $a$ " signifies that welfare families differ from poor non-welfare, " $b$ " that welfare differ from not poor, and " $c$ " that poor non-welfare differ from not poor. The number of welfare families ranges from 49 to 52 , the number of poor from 37 to 38 , and the number of not-poor from 218 to 230 .

of these significance tests needs to be recognized. For example, the power to detect a small effect (.10-.15; generally that expected in the social and behavioral sciences [Cohen, 1987]) of family type in a one-way analysis of variance test $(p<.05)$ is .35 to $.69 .{ }^{4}$ Thus, if the true effect is small, the probability of rejecting the null hypothesis is not particularly high (Cohen, 1987). For this reason, we also report results of family type at a significance level of $p<.10$ for a conservative estimate of Type 2 errors; these results are referred to as marginally significant.

4. The power to detect differences between the poor welfare and the poor non-welfare groups is particularly low; the reader should interpret null results of this comparison with caution. However, alternative specifications for testing mean differences ( $t$ tests using a welfare/non-welfare dummy variable) did not change the pattern of effects reported here
Differences in Parenting Practices and ParentAdolescent Relationships

Levels of maternal nurturance were highest among non-poor families and lowest among poor non-welfare families. Interestingly, levels of effective family management behaviors exhibited a different pattern, with highest scores among the poor nonwelfare families, and lowest among the welfare families. Although these differences were in the range of one-third to one-half of 1 standard deviation, neither was significantly different at $p<.05$. The mean levels of parent-adolescent communication were similar across the three groups and indicated that adolescents communicated with their mothers about various things about once a week, on average. In terms of parent-child conflict, the difference of about onehalf of 1 standard deviation between the welfare and 
non-poor families was significantly different $(p<$ $.05)$, with non-poor mothers reporting fewer conflicts with their adolescents. However, for all three groups, it is important to note that scores fall between 2, indicating that conflicts occur "rarely," and 3 , indicating that they occur "sometimes."

\section{Differences in Adolescent Attitudes and Behaviors}

Adolescents in all three family types endorse about the same level of moral disengagement. On average, youth "disagree" with the 20 statements endorsing deviant or illegal activities. The adolescents also expressed similarly strong beliefs about the importance of school for getting ahead in life.

Non-poor adolescents have levels of academic performance that are approximately one-half of 1 standard deviation above poor non-welfare adolescents and adolescents in welfare-reliant families. The difference between non-poor adolescents and adolescents in welfare-reliant families is statistically significant $(p<.05)$. In contrast, levels of adolescent problem behavior were similar across all three family types.

\section{Differences in Family Characteristics}

As expected, there were striking differences across the three family types in several of the demographic characteristics, particularly those that are known to be related to poverty and welfare status (Blank, 1989; Duncan \& Brooks-Gunn, 1997). Non-poor families were significantly $(p<.05)$ more likely to be comprised of two parents than either welfare families or poor non-welfare families. Although $51 \%$ of non-poor families had two parents present, only $32 \%$ of poor non-welfare and $8 \%$ of welfare families did. Because we are using AFDC to define welfare, the low percentage of two-parent welfare families is to be expected, given that there are relatively few twoparent welfare households (U.S. House of Representatives, 1996). Non-poor families were significantly $(p<.05)$ less crowded than both welfare and poor non-welfare families.

\section{Differences in Characteristics of Mothers and Adolescents}

Differences in characteristics of the mothers also varied in expected ways across the three groups (U.S. House of Representatives, 1996). Although $64 \%$ of the total sample is African American, nearly $88 \%$ of the welfare families are African American, whereas only $53 \%$ of the non-poor families are African American. Education status also varied by family type. Al- though nearly $75 \%$ of all mothers had a high school degree or its equivalent, non-poor mothers were significantly $(p<.05)$ more likely to have a degree than all other mothers. Mothers who received welfare were significantly $(p<.05)$ less likely to be employed than other mothers and were significantly $(p<.05)$ younger than non-poor mothers. There were no differences in the gender or age distributions of adolescents across the three family types.

\section{Differences in Economic Characteristics}

Family economic characteristics varied in expected ways across the three groups. Non-poor families reported significantly $(p<.05)$ fewer economic constraints than did either welfare or poor nonwelfare families. As expected, highly significant differences exist in families' lifetime duration of welfare receipt. Non-poor families had the least amount of lifetime welfare receipt, whereas welfare families had the greatest. The differences between all three groups were statistically significant $(p<.05)$.

\section{Differences in Neighborhood Characteristics}

Families did not differ in their reports of problems in the neighborhood. Families did differ in reports of social control in the neighborhood and the percentages of poor families and vacant houses in the census tract. Non-poor families reported significantly $(p<$ $.05)$ more neighborhood social control and had significantly $(p<.05)$ fewer vacant houses in the census tract than did poor non-welfare families. Non-poor families also lived in census tracts with significantly $(p<.05)$ fewer poor families than did both poor nonwelfare and welfare families.

Hierarchical Multiple Regressions Predicting Family Processes and Adolescent Adjustment

In each multiple regression analysis, the independent variables were grouped and entered into the regression equation based on theoretical support for their independent contributions to family processes and adolescent adjustment. The variables were entered into the regression equations in a step-wise fashion. In each analysis, the individual and family demographic characteristics were entered first into the regression equation. At the second step, the two family economic circumstance variables were entered into the equation. At the third step, we entered the neighborhood context variables. The family welfare status variables were entered last into the regression equation to determine if they made an indepen- 
Table 2 Multiple Regression Ordinary Least Squares (OLS) for Parent Outcome Variables: Coefficients from Final Models

\begin{tabular}{|c|c|c|c|c|c|c|c|c|}
\hline \multirow[b]{3}{*}{ Predictor } & \multicolumn{4}{|c|}{ Parenting } & \multicolumn{4}{|c|}{ Relationship } \\
\hline & \multicolumn{2}{|c|}{ Nurturance } & \multicolumn{2}{|c|}{ Management } & \multicolumn{2}{|c|}{ Conflict } & \multicolumn{2}{|c|}{ Communicate } \\
\hline & $B$ & $\beta$ & $B$ & $\beta$ & $B$ & $\boldsymbol{\beta}$ & $B$ & $\beta$ \\
\hline Intercept & $1.24^{+}$ & $n a$ & -.87 & $n a$ & $2.34^{* *}$ & $n a$ & $6.14^{* *}$ & $n a$ \\
\hline $\begin{array}{l}\text { Family type dummy variables: } \\
\text { Welfare (omitted) } \\
\text { Poor non-welfare } \\
\text { Not poor }\end{array}$ & $\begin{array}{r}\cdots \\
-.07 \\
.01\end{array}$ & $\begin{array}{r}1 \\
-.03 \\
.01\end{array}$ & $\begin{array}{l}\cdots \\
.35^{*} \\
.18\end{array}$ & $\begin{array}{l}\cdots \\
.18 \\
.13\end{array}$ & $\begin{array}{r}\cdots \\
-.19 \\
-.08\end{array}$ & $\begin{array}{l}\cdots \\
-.08 \\
-.05\end{array}$ & $\begin{array}{r}\ldots \\
-.02 \\
.05\end{array}$ & $\begin{array}{r}\cdots \\
-.01 \\
.02\end{array}$ \\
\hline $\begin{array}{l}\text { Neighborhood variables: } \\
\% \text { Poor families } \\
\% \text { Vacant houses } \\
\text { Low neighborhood problems } \\
\text { Social control }\end{array}$ & $\begin{array}{r}-.01 \\
-.01 \\
.03 \\
.09\end{array}$ & $\begin{array}{r}-.05 \\
-.08 \\
.02 \\
.08\end{array}$ & $\begin{array}{c}.01 \\
-.02^{+} \\
.11 \\
.05\end{array}$ & $\begin{array}{r}.10 \\
-.10 \\
.07 \\
.05\end{array}$ & $\begin{array}{r}-.01 \\
.02 \\
-.15 \\
-.03\end{array}$ & $\begin{array}{r}-.06 \\
.08 \\
-.09 \\
-.02\end{array}$ & $\begin{array}{r}-.01 \\
-.01 \\
-.05 \\
.11\end{array}$ & $\begin{array}{r}-.04 \\
-.01 \\
-.02 \\
.07\end{array}$ \\
\hline $\begin{array}{l}\text { Economic characteristics: } \\
\text { Lack of economic strain } \\
\text { Length welfare history }\end{array}$ & $\begin{array}{r}.06 \\
-.02\end{array}$ & $\begin{array}{r}.08 \\
-.04\end{array}$ & $\begin{array}{l}.07 \\
.01\end{array}$ & $\begin{array}{l}.09 \\
.01\end{array}$ & $\begin{array}{c}-.15^{* *} \\
.02\end{array}$ & $\begin{array}{r}-.17 \\
.05\end{array}$ & $\begin{array}{r}.02 \\
-.03\end{array}$ & $\begin{array}{r}.02 \\
-.06\end{array}$ \\
\hline $\begin{array}{l}\text { Family variables: } \\
\text { Two-parent structure }(1=\text { yes }) \\
\text { Crowding }\end{array}$ & $\begin{array}{l}-.12 \\
-.13^{*}\end{array}$ & $\begin{array}{l}-.08 \\
-.12\end{array}$ & $\begin{array}{l}.11 \\
.04\end{array}$ & $\begin{array}{l}.08 \\
.04\end{array}$ & $\begin{array}{r}-.06 \\
.05\end{array}$ & $\begin{array}{r}-.04 \\
.04\end{array}$ & $\begin{array}{r}.03 \\
-.06\end{array}$ & $\begin{array}{r}.01 \\
-.03\end{array}$ \\
\hline $\begin{array}{l}\text { Mother variables: } \\
\text { Race }(1=\text { Black }) \\
\text { H.S. degree }(1=\text { yes }) \\
\text { Age } \\
\text { Employed }(1=\text { yes })\end{array}$ & $\begin{array}{l}.27^{*} \\
.37^{* *} \\
-.01 \\
-.02\end{array}$ & $\begin{array}{r}.18 \\
.18 \\
-.03 \\
-.01\end{array}$ & $\begin{array}{l}.36^{* *} \\
.07 \\
-.01 \\
-.02\end{array}$ & $\begin{array}{r}.27 \\
.04 \\
-.05 \\
-.01\end{array}$ & $\begin{array}{c}.14 \\
-.02 \\
.01^{+} \\
-.07\end{array}$ & $\begin{array}{r}.09 \\
-.01 \\
.10 \\
-.04\end{array}$ & $\begin{array}{c}.30^{*} \\
-.22 \\
.01 \\
-.36^{*}\end{array}$ & $\begin{array}{r}.14 \\
-.07 \\
.02 \\
-.16\end{array}$ \\
\hline $\begin{array}{l}\text { Adolescent variables: } \\
\text { Gender }(1=\text { female }) \\
\text { Age }\end{array}$ & $\begin{array}{l}-.11 \\
-.11 * *\end{array}$ & $\begin{array}{l}-.08 \\
-.18\end{array}$ & $\begin{array}{r}-.11 \\
.01\end{array}$ & $\begin{array}{r}-.09 \\
.01\end{array}$ & $\begin{array}{l}.01 \\
.03\end{array}$ & $\begin{array}{l}.01 \\
.04\end{array}$ & $\begin{array}{c}.10 \\
-.21 * *\end{array}$ & $\begin{array}{r}.05 \\
-.23\end{array}$ \\
\hline $\begin{array}{l}\text { Adjusted } R^{2} \\
R^{2}\end{array}$ & $\begin{array}{l}.12^{* *} \\
.17\end{array}$ & & $\begin{array}{l}.07^{* *} \\
.12\end{array}$ & & $\begin{array}{l}.05^{* *} \\
.10\end{array}$ & & $\begin{array}{l}.06^{* *} \\
.11\end{array}$ & \\
\hline
\end{tabular}

Note: $\mathrm{na}=$ not applicable.

${ }^{+} p<.10 ;{ }^{*} p<.05 ;{ }^{* *} p<.01$.

dent contribution to family process and adolescent adjustment. Unstandardized and standardized regression coefficients from the final models for the parenting and parent-adolescent relationship outcomes are illustrated in Table 2. The corresponding information for the adolescent attitude and behavior outcomes is presented in Table 3.

\section{Predicting Parenting Behaviors}

Parent nurturance. At Step 1, the individual and family demographic characteristics made a significant contribution to the model, $F(8,311)=6.20, p<$ .001 . Within this block, the individual variables representing mothers' education and ethnicity, adolescents' age, and crowding in the household were significant $(p<.05)$. Specifically, mothers with high school degrees, African American mothers, those with younger children, and those in less crowded households reported more nurturance. This block explained $14 \%$ of the variance in parent nurturance. Entering the economic circumstance variables at Step 2 did not add significantly to the model and did not change the strength of the significant Step 1 predictors. The Step 3 variables, neighborhood context, were also nonsignificant. Lastly, the variables entered at Step 4 measuring family welfare status were nonsignificant. The final model explained $17 \%$ of the variance in parent nurturance, with the variables that were significant in Step 1 remaining so in the final model.

Parent management effectiveness. At Step 1, the individual and family demographic characteristics made a significant contribution to the model, $F(8,311)=$ $3.25, p<.01$. Within this block, the variable representing mothers' ethnicity was significant $(p<.01)$, 
Table 3 Multiple Regression Ordinary Least Squares (OLS) for Adolescent Outcome Variables: Coefficients from Final Models

\begin{tabular}{|c|c|c|c|c|c|c|c|c|}
\hline \multirow[b]{3}{*}{ Predictor } & \multicolumn{4}{|c|}{ Attitudes } & \multicolumn{4}{|c|}{ Behaviors } \\
\hline & \multicolumn{2}{|c|}{$\begin{array}{c}\text { Moral } \\
\text { Disengagement }\end{array}$} & \multicolumn{2}{|c|}{$\begin{array}{c}\text { School } \\
\text { Importance }\end{array}$} & \multicolumn{2}{|c|}{ Academic } & \multicolumn{2}{|c|}{$\begin{array}{l}\text { Problem } \\
\text { Behavior }\end{array}$} \\
\hline & $B$ & $\beta$ & $B$ & $\beta$ & $B$ & $\beta$ & $B$ & $\beta$ \\
\hline Intercept & $1.70^{* * *}$ & $n a$ & $3.48^{* *}$ & & -.02 & na & $-1.37^{*}$ & na \\
\hline $\begin{array}{l}\text { Family type dummy variables: } \\
\text { Welfare (omitted) } \\
\text { Poor non-welfare } \\
\text { Not poor }\end{array}$ & $\begin{array}{r}\cdots \\
-.18 \\
-.13\end{array}$ & $\begin{array}{c}\cdots \\
-.11 \\
-.11\end{array}$ & $\begin{array}{l}- \\
-.24^{*} \\
-.12\end{array}$ & $\begin{array}{l}\cdots \\
-.16 \\
-.11\end{array}$ & $\begin{array}{r}\cdots \\
-.09 \\
-.09\end{array}$ & $\begin{array}{l}\cdots \\
-.04 \\
-.05\end{array}$ & $\begin{array}{r}\ldots \\
-.01 \\
-.06\end{array}$ & $\begin{array}{r}. . \\
-.01 \\
-.04\end{array}$ \\
\hline $\begin{array}{l}\text { Neighborhood variables: } \\
\% \text { Poor families } \\
\% \text { Vacant houses } \\
\text { Low neighborhood problems } \\
\text { Social control }\end{array}$ & $\begin{array}{l}-.01^{*} \\
.02^{+} \\
-.05 \\
-.04\end{array}$ & $\begin{array}{r}-.14 \\
.11 \\
-.04 \\
-.05\end{array}$ & $\begin{array}{l}.01 \\
.01 \\
.01 \\
.03\end{array}$ & $\begin{array}{l}.01 \\
.01 \\
.01 \\
.04\end{array}$ & $\begin{array}{r}-.01 \\
.01 \\
.13 \\
-.02\end{array}$ & $\begin{array}{r}-.02 \\
.06 \\
.07 \\
-.02\end{array}$ & $\begin{array}{r}-.01 \\
.01 \\
.03 \\
-.13^{*}\end{array}$ & $\begin{array}{r}-.08 \\
.07 \\
.02 \\
-.12\end{array}$ \\
\hline $\begin{array}{l}\text { Economic characteristics: } \\
\text { Lack of economic strain } \\
\text { Length welfare history }\end{array}$ & $\begin{array}{l}.01 \\
.01\end{array}$ & $\begin{array}{l}.02 \\
.01\end{array}$ & $\begin{array}{r}.02 \\
-.01\end{array}$ & $\begin{array}{r}.04 \\
-.04\end{array}$ & $\begin{array}{c}.15^{* *} \\
-.06^{+}\end{array}$ & $\begin{array}{r}.16 \\
-.13\end{array}$ & $\begin{array}{l}-.03 \\
-.01\end{array}$ & $\begin{array}{l}-.04 \\
-.04\end{array}$ \\
\hline $\begin{array}{l}\text { Family variables: } \\
\text { Two-parent structure }(1=\text { yes }) \\
\text { Crowding }\end{array}$ & $\begin{array}{r}-.03 \\
.02\end{array}$ & $\begin{array}{r}-.03 \\
.03\end{array}$ & $\begin{array}{l}-.16^{*} \\
-.01\end{array}$ & $\begin{array}{l}-.16 \\
-.01\end{array}$ & $\begin{array}{c}.08 \\
-.19^{* *}\end{array}$ & $\begin{array}{r}.05 \\
-.16\end{array}$ & $\begin{array}{l}-.23^{* *} \\
-.09\end{array}$ & $\begin{array}{l}-.17 \\
-.09\end{array}$ \\
\hline $\begin{array}{l}\text { Mother variables: } \\
\text { Race }(1=\text { Black }) \\
\text { H.S. degree }(1=\text { yes }) \\
\text { Age } \\
\text { Employed }(1=\text { yes })\end{array}$ & $\begin{array}{r}-.01 \\
.08 \\
.01 \\
-.02\end{array}$ & $\begin{array}{r}-.01 \\
.05 \\
.06 \\
-.02\end{array}$ & $\begin{array}{r}.01 \\
.05 \\
-.01 \\
.09\end{array}$ & $\begin{array}{r}.01 \\
.03 \\
-.03 \\
.09\end{array}$ & $\begin{array}{l}-.05 \\
.36^{* *} \\
-.01 \\
.04\end{array}$ & $\begin{array}{r}-.03 \\
.16 \\
-.01 \\
.03\end{array}$ & $\begin{array}{l}-.21^{* *} \\
.01 \\
.01 \\
-.03\end{array}$ & $\begin{array}{r}-.17 \\
.01 \\
.08 \\
-.02\end{array}$ \\
\hline $\begin{array}{l}\text { Adolescent variables: } \\
\text { Gender }(1=\text { female }) \\
\text { Age }\end{array}$ & $\begin{array}{c}-.17^{* *} \\
.06^{*}\end{array}$ & $\begin{array}{r}-.16 \\
.13\end{array}$ & $\begin{array}{l}.06 \\
.01\end{array}$ & $\begin{array}{l}.06 \\
.01\end{array}$ & $\begin{array}{c}.26^{* *} \\
-.05\end{array}$ & $\begin{array}{r}.16 \\
-.08\end{array}$ & $\begin{array}{r}-.20^{* *} \\
.15^{* *}\end{array}$ & $\begin{array}{r}-.15 \\
.26\end{array}$ \\
\hline $\begin{array}{l}\text { Adjusted } R^{2} \\
R^{2}\end{array}$ & $\begin{array}{l}.03^{+} \\
.08\end{array}$ & & $\begin{array}{l}.01 \\
.05\end{array}$ & $n . s$. & $\begin{array}{l}.16^{* *} \\
.20\end{array}$ & & $\begin{array}{l}.13^{* *} \\
.17\end{array}$ & \\
\hline
\end{tabular}

Note: na $=$ not applicable.

${ }^{+} p<.10 ;{ }^{*} p<.05 ;{ }^{* *} p<.01$.

such that African American mothers reported more effective management practices than did their European American counterparts. The two-parent family structure variable was also significant $(p<.05)$, such that married or partnered mothers reported more effective management practices. This block explained $8 \%$ of the variance in parent management effectiveness. Entering the economic circumstance variables at Step 2 did not add significantly to the model, but eliminated the significance of the two-parent family structure variable. The Step 3 variables, neighborhood context, also failed to make a significant contribution to the model. The block entered at Step 4, family welfare status, was marginally significant $(p<.06)$. The dummy variable for poor non-welfare families was significant at $p<.02$, indicating that poor non-welfare families reported higher levels of effective management than their welfare counterparts. The final model explained $12 \%$ of the variance in management effectiveness. Significant $(p<.05)$ individual predictors of management effectiveness in the final model were mothers' ethnicity and the poor non-welfare family type variable.

\section{Predicting Parent-Adolescent Relationships}

Parent-adolescent conflict. At Step 1, the individual and family demographic characteristics made a significant contribution to the model, $F(8,311)=2.06$, $p<.05$, and explained $5 \%$ of the variance, although no individual variable was significant at $p<.05$. Entering the economic circumstance variables at Step 2 added significantly to the model; this effect was due entirely to the effects of economic strain, which was 
significant at $p<.01$. Families experiencing less economic strain had lower levels of parent-adolescent conflict. The Step 3 variables, neighborhood context, did not make a significant contribution to the model, although the variable for maternal age also became marginally significant $(p<.10)$ at this step, indicating that older mothers had slightly more conflict with their adolescents. The variables entered at Step 4 measuring family welfare status did not add significantly to the model. The final model explained $10 \%$ of the variance in parent-adolescent conflict. Economic strain, which was positively associated with parentadolescent conflict, remained highly significant $(p<$ .01 ), whereas maternal age remained marginally so $(p<.09)$.

Parent-adolescent communication. At Step 1, the individual and family demographic characteristics made a significant contribution to the model, $F(8,311)=$ $4.01, p<.01$. Within this block, the variables representing mothers' employment was significant $(p<$ $.05)$, such that the youth of employed mothers reported less parent-child communication. Child age was also significant $(p<.01)$; older adolescents reported less communication with their mothers. This block explained $9 \%$ of the variance in parent-child communication. Entering the economic circumstance variables at Step 2 did not add to or change the significance of the variables in the model. The Step 3 variables, neighborhood context, were nonsignificant, although adding them strengthened the significance of the ethnicity variable to $p<.05$. The variables entered at Step 4 measuring family welfare status were also nonsignificant. The final model explained $11 \%$ of the variance in parent-adolescent communication. Ethnicity, adolescent age, and maternal employment all remained significant at this step.

\section{Predicting Adolescent Attitudes and Behaviors}

Moral disengagement. At Step 1, the individual and family demographic characteristics made a significant contribution to the model, $F(8,311)=2.17, p<$ .05 , and explained $5 \%$ of the variance in moral disengagement. Individual significant $(p<.05)$ variables in this block included adolescents' gender and age. Specifically, girls and younger adolescents were less likely to agree with statements endorsing moral disengagement than were their male and older counterparts. Entering the economic circumstance variables at Step 2 did not add to or change the model. The Step 3 variables, neighborhood context, did not make a significant contribution to the model as a block, although the variable for the percentage of poor fami- lies in the census tract was significant $(p<.05)$. The direction of this relation indicated that adolescents living in census tracts with more poor families were less likely to agree with statements endorsing moral disengagement. The variables entered at Step 4 measuring family welfare status were nonsignificant and did not change the model from Step 3 . The final model explained $8 \%$ of the variance in moral disengagement; variables representing adolescent gender and age and percentage of poor families in the census tract remained significant.

Beliefs about importance of education. The Step 1 variables, individual and family demographic characteristics, did not make a significant contribution to the model, $F(8,311)=1.36$, n.s., although the variable for two-parent family structure was significant $(p<.05)$ such that youth in two-parent families attach less importance to the value of education for getting ahead in life than do their one-parent counterparts. Entering the economic circumstance variables at Step 2 did not add to or change the model, nor did the Step 3 variables (neighborhood context). The Step 4 variables, family welfare status, did not add significantly to the model, although the coefficient for poor non-welfare status was negative and significant $(p<.05)$, indicating that youth in poor non-welfare families attach less importance to the value of education for getting ahead in life than do their welfare counterparts. However, the final model explained only $5 \%$ of the variance and failed to reach significance.

Academic achievement. At Step 1, the individual and family demographic characteristics made a significant contribution to the model, $F(8,311)=6.64, p<$ .001 , and explained $15 \%$ of the variance in academic achievement. Individual significant $(p<.01)$ variables in this block included mothers' education status, adolescents' gender, and family crowding. Specifically, having a mother with a high school degree, being female, and living in a less crowded family environment were related to higher academic achievement among adolescents.

Entering the economic circumstance variables at Step 2 added significantly to the model and reduced the effects of adolescent age to nonsignificance. The significance of this block was due primarily to economic strain $(p<.01)$, and secondarily $(p<.09)$ to families' welfare history. Adolescents in families experiencing less economic strain performed better in school, and adolescents in families with greater welfare experience were slightly more likely to do worse in school. The Step 3 variables, neighborhood context, did not make a significant contribution to the model and did not change the significance of the Step 2 variables. The variables entered at Step 4 measuring 
family welfare status were also nonsignificant. The final model explained $20 \%$ of the variance in academic achievement, with most significant variables at Step 1 and Step 2 (mothers' education, adolescent gender, household crowding, economic strain, and, to a lesser extent, families' welfare history) remaining significant in the final model.

Problem behavior. At Step 1, the individual and family demographic characteristics made a significant contribution to the model, $F(8,311)=6.78, p<.001$. Within this block, the marital status and ethnicity variables as well as adolescent gender and age variables were significant $(p<.01)$. Adolescents living with married or partnered mothers, younger adolescents, girls, and African American adolescents reported less engagement in problem behavior. This block explained $15 \%$ of the variance in problem behavior. Entering the economic circumstance variables at Step 2 did not add significantly to or change the model. The Step 3 variables, neighborhood context, did not add significantly as a block, although within this block the social control variable was significant $(p<.05)$. Specifically, more neighborhood social control was related to less adolescent problem behavior. The variables entered at Step 4 measuring family welfare status were nonsignificant and did not change the Step 3 model. The final model explained 17\% of the variance in adolescent problem behavior, with the significant variables from Step 1 and Step 4 (parent marital status, ethnicity, adolescent gender and age, and neighborhood social control) remaining significant in the final model.

\section{DISCUSSION}

The present study allowed for an observation of the independent relations of welfare receipt to family processes and adolescent adjustment net of neighborhood conditions and family characteristics known to be related to these factors. What support did we find for the competing theories regarding predictors of family processes and adolescent adjustment? Taken together, our results demonstrate that welfare and its correlates affect various dimensions of family process and adolescent adjustment differently. We will discuss the results supporting each theoretical perspective in turn.

First, we found broad effects of the family demographic variables on the outcomes in our analysis. Specifically, maternal education was related to increased nurturance, greater parent-adolescent communication, and higher academic achievement among adolescents. This result supports previous arguments that identify maternal education as an im- portant demographic resource, particularly among low-income children (Corcoran, 1995; Weston, 1989). For example, mothers' general aspirations for children's educational attainment may be higher among mothers with high school degrees. Parental expectations, in turn, have been shown to be important predictors of children's academic performance (Barber \& Eccles, 1992).

In contrast to the positive effects of maternal education, we found negative effects of household crowding on parental nurturance and youth academic achievement. This result parallels those of previous studies that suggest that crowding is an important indicator of the resources available to individuals in the household (Corcoran \& Bogess, 1994).

Unlike previous studies, which generally report salubrious effects of maternal employment on family functioning, we found a negative effect of maternal employment on youth reports of communication with their mothers. This effect may be due to employed mothers in this lower-income sample having less time or energy available to interact with their children or to other, unmeasured effects that maternal employment may have on family processes. Future research, particularly that which monitors the effects of transitions to work among welfare-reliant families, should pursue this question and investigate which aspects of maternal employment, such as the number of hours worked, the time of the work shifts, or the complexity of job tasks, might affect family processes.

We also found effects of ethnicity such that African American mothers reported greater nurturance and more effective management practices, and African American youth in the study reported more communication with their mothers and fewer problem behaviors than their European American counterparts. Similar studies have suggested that African American parents in low-income neighborhoods do not generally perceive the community to be responsive to their needs and hence may engage in more promotive and protective activities than their European American counterparts to ensure a protective environment for their children (Elder et al., 1995; McLoyd \& Wilson, 1991). Because effective management is highly linked to youth problem behavior, it is not surprising that the African American adolescents in this sample were engaging in fewer problem behaviors.

We found fewer effects of the economic circumstance variables, our second set of potentially important variables. Family economic strain was associated with increased parent-adolescent conflict and lower academic achievement among adolescents. This re- 
sult supports the hypothesis that parents' subjective perceptions of their economic situations are important predictors of family processes. ${ }^{5}$

The neighborhood effects hypothesis gained some modest support in our investigation. Three outcomes-parent management effectiveness, adolescent endorsement of moral disengagement, and adolescent problem behavior-were related to the neighborhood context variables. Effective parent management and youth adherence to mainstream moral values were marginally inversely related to the percent of vacant houses in the neighborhood. Social control in the neighborhood was related to less problem behavior among adolescents. The finding that youth in census tracts with greater numbers of poor families were less likely to endorse deviant moral values was in contrast to our theoretical prediction. This result suggests that structural resources (e.g., inadequate housing) within poor neighborhoods are related to different outcomes than are social capital resources (e.g., the number of poor families or individuals). In general, however, these results are in line with established sociological theory regarding the effects of neighborhood social disorganization and social environments on youth problem behavior. Such theories suggest that disrupted family functioning and adolescent problem behaviors are highest in neighborhoods characterized by limited resources and a lack of adults who help steer adolescents toward conventional trajectories of social and economic success (Brewster, 1994; Furstenberg, 1990). Future research is needed to more clearly describe the meaning of such neighborhood characteristics, that is, families' interpretation of and response to them. For example, families who live in neighborhoods with high concentrations of poor families may make a greater effort to instill conventional moral values in their adolescents, thereby minimizing the chances that youth will become engaged in problem behavior. Such a proactive approach may not be necessary in lowerrisk neighborhoods.

What about the relation of welfare receipt to family process? We were especially interested in providing support for or against the hypothesis that welfare

5. In fact, they may be more important than static indicators of household income. We tested alternative specifications of the regression models (not reported here) with the natural log of household income entered as an individual predictor in the economic characteristics block, and a welfare/non-welfare dummy variable entered alone in the last block. Household income was not significantly related $(p<.10)$ to any of the outcome measures. The welfare dummy variable was significantly negatively related $(p<.05)$ to effective parent management only. is related to family processes and adjustment during adolescence. Our results do not warrant the conclusion that welfare by itself is related to these outcomes. However, we did find one difference: relative to mothers in welfare families, mothers in poor nonwelfare families reported being more effective in the ways they monitored, supervised, and disciplined their adolescents. Because we controlled for family income and other stressors in the environment such as inadequate housing and dangerous neighborhoods, these variables, often cited in the developmental literature as correlates of effective parenting (e.g., McLoyd, 1990), cannot explain this finding. Future research is needed to understand whether and how other, unmeasured aspects of the ecological environments of welfare recipients might affect family processes relative to non-welfare families among families with older children.

This finding could be interpreted in light of results presented by Zill et al. (1991), who reported that children in welfare families had less optimal home environments, measured in terms of support for emotional health and school achievement, relative to their poor non-welfare counterparts. Possibly, the present measure of parent management effectiveness at adolescence reflects comparable underlying processes to the parenting behaviors examined by Zill and his colleagues. Conversely, the result may be related to an unmeasured variable common to both studies' parenting measure, such as parent mental health, which is known to affect parenting behaviors (Conger \& Elder, 1994; Downey \& Coyne, 1990). Longitudinal data would make a test of this hypothesis possible. Such data would allow researchers to examine the stability of parenting practices in welfare-reliant families over time and also to identify the antecedents of effective management among parents of adolescents.

The analyses presented in this study must be viewed in light of several limitations. First, we lack data on lifetime poverty status and monthly spells of welfare receipt. Research has indicated substantial fluidity in welfare and poverty status among lowincome families (Pavetti, 1994; Yoshikawa, 1997), which has important implications for assigning families to one of our three family types. For example, Pavetti (1994), using monthly data from the NLSY to investigate duration of welfare receipt, found widespread evidence for families' cycling between welfare and poverty. Others (Korenman, Miller, \& Sjaastad, 1995; McLeod \& Shanahan, 1993) have discussed the importance of chronic versus intermittent poverty for family processes and children's outcomes. Monthly data on welfare receipt would allow us to test the 
hypothesis that using the previous 12 months' welfare history to define receipt affected our analyses. It would also allow us to minimize the overlap between the poor welfare and poor non-welfare group. For example, adopting an 18 or 24 month history to define welfare receipt may have shifted the composition of the poor non-welfare group. Unfortunately, few extant data sets with rich measures of family process such as those presented here provide such detailed information on welfare use. Yet, given the evidence for cycling documented by Pavetti and others, this approach is preferable for future studies.

A strength of our multivariate analyses is that they controlled for an unusually large number of theoretically relevant selection effects. At the same time, the sample size limited the power of our tests to detect small effects of welfare by itself (Cohen, 1987). Therefore, although our analyses do not support the conclusion that welfare families differ in dramatic ways from their non-welfare counterparts, these null results cannot be taken as evidence that such differences do not exist. Future research replicating these analyses with larger sample sizes is necessary to establish the negligibility of welfare effects on family processes. Our results suggest that although welfare is unlikely to be related to adolescent attitudes and behaviors, it may be related to some parenting behaviors, such as parent management. These and other parenting behaviors may in turn be related to additional important outcomes, such as youth mental health, which we did not investigate.

As in all survey research, the limitations of selfreport and the possibilities of acquiescence must be considered, especially given the demand characteristics of the questions in this study. However, a strength of our data is its reliance on multiple informants for various measures. For example, the measures of adolescent adjustment were primarily collected directly from the adolescent, and not from parental reports of adolescent behavior that may be biased due to lack of information or other parent and environmental characteristics (Demo \& Acock, 1996).

What do our results contribute to the current policy debate over welfare effects on families? If results from the present study had revealed substantial differences between welfare and non-welfare families, they might have lent support to the argument that welfare by itself is harmful to children and families and that eliminating its entitlement could benefit parents and children. However, our results provide little empirical support for these popular claims (Salomon, 1996; Sidel, 1996). We found scant evidence to support stereotypes portraying mothers in welfare- reliant families as less good at parenting and relating with their children, and portraying adolescents whose attitudes, values, and behaviors deviate from those of other families.

Instead, we found that a constellation of welfare correlates such as family demographic characteristics, economic strain, and neighborhood context variables were more likely to be related to the family process and youth adjustment variables we examined. Therefore, if the goal of policy is to improve the academic achievement of youth, for example, attention would be better directed toward decreasing families' economic struggles or increasing maternal education.

Although we found little association of welfare by itself with family relationships and youth outcomes, we did find some significant relations of variables that may be affected by welfare reform. Based on these cross-sectional data, we cannot demonstrate whether families leaving welfare will change on any of these correlates of family functioning. However, if some families leaving welfare experience greater economic strain or increased crowding, as some analysts have speculated (Bane, 1997; Edelman, 1997), results from our data suggest that children may be at risk for decreased parental nurturance, greater parent-adolescent conflict, and poorer academic outcomes. Therefore, one policy prescription might be to monitor families over time as they make welfareto-work transitions and see whether variables such as family economic strain and crowding increase or decrease and for whom these effects occur. Such studies could also monitor concomitant changes in family functioning and children's well-being. Policy solutions such as helping mothers on welfare obtain jobs that pay sufficient wages and thereby mitigate economic strain during the transition from welfare to work might then be appropriate for some families.

\section{ACKNOWLEDGMENTS}

This research was supported by an NICHD predoctoral training grant fellowship (T5 T32-HD07109-17) and an NICHD Individual National Research Service Award (1 F32 HD08145-01) to the first author and by a grant from the MacArthur Foundation Research Network on Successful Adolescent Development Among Youth in High-Risk Settings to the second author. We appreciate the contribution of the participating families as well as Frank F. Furstenberg, Jr., Arnold J. Sameroff, Glen H. Elder, Jr., Tom D. Cook, Lynne M. Geitze, Julian O. Teitler, Sarah E. Lord, and W. Todd Bartko. We also thank Sheldon H. Danziger for helpful comments. Portions of this article were 
presented at the March 1995 meetings of the Society for Research in Child Development, Indianapolis, IN.

\section{ADDRESSES AND AFFILIATIONS}

Corresponding author: Ariel Kalil, Program on Poverty and Social Welfare Policy, University of Michigan, 540 East Liberty Street, Ann Arbor, MI 481042210; e-mail: akalil@umich.edu. Jacquelynne S. Eccles is also at the University of Michigan.

\section{REFERENCES}

Alessandri, S. M. (1992). Effects of maternal work status in single-parent families on children's perception of self and family and school achievement. Journal of Experimental Child Psychology, 54, 417-433.

Bane, M. (1997). Welfare as we might know it. The American Prospect, 30, 47-53.

Barber, B. L., \& Eccles, J. S. (1992). Long-term influence of divorce and single parenting on adolescent family- and work-related values, behaviors, and aspirations. Psychological Bulletin, 111, 108-126.

Baumrind, D. (1989). Rearing competent children. In W. Damon (Ed.), Child development today and tomorrow (pp. 349-378). San Francisco: Jossey-Bass.

Baumrind, D. (1991). The influence of parenting style on adolescent competence and substance abuse. Journal of Early Adolescence, 11, 56-94.

Brewster, K. (1994). Race differences in sexual activity among adolescent women: The role of neighborhood characteristics. American Sociological Review, 59, 408-424.

Brooks-Gunn, J., Duncan, G., Klebanov, P., \& Sealand, N. (1993). Do neighborhoods influence child and adolescent development? American Journal of Sociology, 99, 335395.

Cohen, J. (1987). Statistical power analysis for the behavioral sciences. Hillsdale, NJ: Erlbaum.

Collins, A., \& Aber, J. L. (1997). Issue Brief 1: How welfare reform can help or hurt children. Columbia University: National Center for Children in Poverty.

Comer, J. P., \& Haynes, N. M. (1991). Parent involvement in schools: An ecological approach. [Special issues]: Educational partnerships; Home-community-school. Elementary School Journal, 91, 271-277.

Condran, G. A., \& Furstenberg, F. (1994). Are trends in the well-being of children related to changes in the American family? Making a simple question more complex. Population, 6, 1613-1638.

Conger, R., \& Elder, G. H., Jr. (1994). Families in troubled times. New York: Walter de Gruyter.

Conger, R. D., Ge, X., Elder, G. H., Lorenz, F. O., \& Simons, R. L. (1994). Economic stress, coercive family processes, and developmental problems of adolescents. Child Development, 65, 541-561.

Connell, J. P., Spencer, M. B., \& Aber, J. L. (1994). Educational risk and resilience in African American youth:
Context, self, action, and outcomes in school. Child Development, 65, 493-506.

Corcoran, M. (1995). Rags to rags: Poverty and mobility in the U.S. Annual Review of Sociology, 21, 237-267.

Corcoran, M., \& Bogess, S. (1994). The intergenerational transmission of poverty and inequality: A review of the literature. Unpublished manuscript, University of Michigan at Ann Arbor.

Demo, D., \& Acock, A. (1996). Family structure, family process, and adolescent well-being. Journal of Research on Adolescence, 6, 457-488.

Dornbusch, S. M., Ritter, P. L., Leiderman, P. H., Roberts, D. F., \& Fraleigh, M. J. (1987). The relations of parenting style to adolescent school performance. Child Development, 58, 1244-1257.

Downey, G., \& Coyne, J. (1990). Children of depressed parents: An integrative review. Psychological Bulletin, 108, $1-27$.

Duncan, G., \& Brooks-Gunn, J. (1997). Consequences of growing up poor. New York: Russell Sage Foundation.

Eccles, J. S., Furstenberg, F., McCarthy, K., \& Lord, S. E. (1992, February). How parents respond to risk and opportunity. Paper presented at the meetings of the Society for Research on Adolescence, Washington, DC.

Edelman, P. (1997, March). The worst thing Bill Clinton has done. The Atlantic Monthly, pp. 43-58.

Elder, G. E., Eccles, J. S., Ardelt, M., \& Lord, S. E. (1995). Inner city parents under economic pressure: Perspectives on the strategies of parenting. Journal of Marriage and the Family, 57, 771-784.

Elliott, D. S., Huizinga, D., \& Ageton, S. S. (1985). Explaining delinquency and drug use. Beverly Hills, CA: Sage.

Elliott, D. S., Huizinga, D., \& Menard, S. (1989). Multiple problem youth: Delinquency, substance use, and mental health problems. New York: Springer-Verlag.

Ensminger, M. E. (1995). Welfare and psychological distress: A longitudinal study of African American urban mothers. Journal of Health and Social Behavior, 36, 346359.

Furstenberg, F. (1990, August). How families manage risk and opportunity in dangerous neighborhoods. Paper presented at the meetings of the American Sociological Association, Washington, DC.

Furstenberg, F., Brooks-Gunn, J., \& Morgan, S. (1987). Adolescent mothers and their children in later life. Family Perspectives, 19, 142-151.

Hoffman, L. (1989). Effects of maternal employment in the two-parent family. American Psychologist, 44, 283-292.

Jessor, R. (1993). Successful adolescent development among youth in high-risk settings. American Psychologist, 48, 117-126.

Kaus, M. (1992). The end of equality. New York: Basic Books.

Klebanov, P. K., Brooks-Gunn, J., \& Duncan, G. J. (1994). Does neighborhood and family poverty affect mothers' parenting, mental health, and social support? Journal of Marriage and the Family, 56, 4412-4455.

Korenman, S., Miller, J., \& Sjaastad, J. (1995). Long-term poverty and child development in the United States: Re- 
sults from the NLSY. Children and Youth Services Review, 17, 127-155.

Lempers, J. D., Clark-Lempers, D., \& Simons, R. L. (1989). Economic hardship, parenting, and distress in adolescence. Child Development, 60, 25-39.

Loeber, R., \& Stouthamer-Loeber, M. (1986). Family factors as correlates and predictors of juvenile conduct problems and delinquency. Chicago: University of Chicago Press.

Lord, S. E. (1994). Parenting in impoverished urban contexts. Unpublished doctoral dissertation, University of Colorado, Boulder.

Maccoby, E. E., \& Martin, J. A. (1983). Socialization in the context of the family: Parent-child interaction. In E. M. Hetherington (Ed.), P. H. Mussen (Series Ed.), Handbook of child psychology: Vol. 4. Socialization, personality, and social development (pp. 1-101). New York: Wiley.

McLanahan, S. S., \& Sandefur, G. (1994). Growing up with a single parent: What hurts, what helps. Cambridge, MA: Harvard University Press.

McLeod, J. D., \& Shanahan, M. J. (1993). Poverty, parenting, and children's mental health. American Sociological Review, 58, 351-366.

McLoyd, V. (1990). The impact of economic hardship on Black families and children: Psychological distress, parenting, and socioemotional development. Child Development, 61, 311-346.

McLoyd, V., \& Wilson, L. (1991). The strain of living poor: Parenting, social support, and child mental health. In A. Huston (Ed.), Children in poverty: Child development and public policy (pp. 105-135). Cambridge: Cambridge University Press.

Mead, L. (1992). The new politics of poverty: The non-working poor in America. New York: Basic.

Montemayor, R. (1983). Parents and adolescents in conflict: All families some of the time and some families most of the time. Journal of Early Adolescence, 3, 83-103.

Moore, K. A., \& Driscoll, A. (1996, May). Deprivation or dependency? Is it depth and duration of poverty or welfare? Paper presented at the meetings of the Population Association of America, New Orleans, LA.

Moore, K. A., Zaslow, M. J., Coiro, M. J., Miller. S. M., \& Magenheim, E. B. (1995). The JOBS evaluation: How well are they faring? AFDC families with preschool-aged children in Atlanta at the outset of the JOBS evaluation. Washington, DC: Department of Health and Human Services, Office of the Assistant Secretary for Planning and Evaluation.

Murray, C. (1984). Losing ground: American social policy 1950-1980. New York: Basic.

Patterson, G., DeBaryshe, B. D., \& Ramsey, E. (1989). A developmental perspective on antisocial behavior. American Psychologist, 44, 329-335.

Patterson, G., \& Stouthamer-Loeber, M. (1984). The correlation of family management practices and delinquency. Child Development, 55, 1299-1307.

Pavetti, L. (1994). Who is affected by time limits? Welfare Reform Briefs, No. 7. Washington, DC: The Urban Institute.
Personal Responsibility and Work Opportunity Reconciliation Act, P.L. 104-193 (1996).

Phillips, D., \& Bridgman, A. (1997). New findings on welfare and children's development. Washington, DC: National Academy Press.

Repetti, R. L., Matthews, K. A., \& Waldron, I. (1989). Employment and women's health. American Psychologist, 44, 1394-1401.

Salomon, A. (1996). Welfare reform and the real lives of poor women. American Journal of Orthopsychiatry, 66, $486-489$.

Sampson, R., \& Laub, J. (1994). Urban poverty and the family context of delinquency: A new look at structure and process in a classic study. Child Development, 65, 523540.

Schneider, B., \& Coleman, J. (1993). Parents, their children, and schools. Boulder, $\mathrm{CO}$ : Westview.

Sidel, R. (1996). The enemy within: A commentary on the demonization of differences. American Journal of Orthopsychiatry, 66, 490-495.

Steinberg, L. (1990). Autonomy, conflict, and harmony in the family relationship. In S. S. Feldman \& G. R. Elliott (Eds.), At the threshold: The developing adolescent (pp. 255276). Cambridge, MA: Harvard University Press.

Steinberg, L., Lamborn, S, Dornbusch, S., \& Darling, N. (1992). Impact of parenting practices on adolescent achievement: Authoritative parenting, school involvement, and encouragement to succeed. Child Development, $63,1266-1281$.

U.S. Bureau of the Census. (1993). Weighted average poverty thresholds for families of specified size. U.S. Bureau of the Census CD-ROM, Income and Poverty. Available at: http:/ / www.census.gov / ftp / pub / hhes / poverty / histpov/hstpov1.prn.

U.S. House of Representatives, Committee on Ways and Means. (1996). Green Book. Washington, DC: Government Printing Office.

Weston, W. J. (1989). Education and the American family. New York: New York University Press.

Wilson, W. J. (1987). The truly disadvantaged: The inner city, the underclass, and public policy. Chicago: University of Chicago Press.

Yeung, W., Brooks-Gunn, J., Duncan, G., \& Smith, J. (1996, April). Does parental welfare dependence harm children? Paper presented at research briefing, Board on Children, Youth, and Families, University of Michigan: Institute for Social Research.

Yoshikawa, H. (1997, April). The impact of welfare dynamics and supports on child mental health: Evidence from the $\mathrm{Na}$ tional Longitudinal Survey of Youth. Paper presented at the meetings of the Society for Research in Child Development, Washington, DC.

Zill, N., Moore, K. A., Smith, E. W., Stief, T., \& Coiro, M. (1991). The life circumstances and development of children in welfare families: $A$ profile based on national survey data. Washington DC: Child Trends, Inc. 